\title{
AMERICAN TELEMEDICINE ASSOCIATION 2012 FALL FORUM
}

\author{
SEPTEMBER 10-11, 2012
}

ROOSEVELT HOTEL

\section{INNOVATIVE PRESENTATIONS ON CUTTING-EDGE TELEMEDICINE APPLICATIONS} AND THE FUTURE OF REMOTE HEALTHCARE

\section{CALL FOR PRESENTATIONS}

The ATA Fall Forum 2012 will follow a similar format to our highly-rated 2011 program, which was filled with unique ideas in an innovative format. We are looking for short talks, two-person dialogues, demonstrations or other inventive presentation formats on a wide range of telemedicine subject areas. Topics might include: a unique approach to delivering telehealth services, a new and better device, a successful way of introducing telemedicine to providers or consumers, a novel way to organize and fund a program, a fresh look at overcoming a barrier.

In 2012, ATA is particularly interested in interview format presentations. If you know someone with an innovative idea for remote healthcare (or if YOU are that person) please consider submitting an Interview abstract.

\section{SubMission Guidelines:}

- 15 Minutes of Fame. All Fall Forum presentations are 15 minutes long. Speakers should plan on speaking the entire 15 minutes, as there will be no in-session question time.

- Be a team player. In 2012 we encourage submitters to consider an interview format, featuring a question and answer format between two stage presenters

- Let's get personal. Make sure your presentation focuses on the "human touch" of telemedicine. Personal stories and experiences are welcome.

- The stage is all yours. The Forum is a one-track meeting. There will be no panel discussions and no breakout sessions. Design your presentation for a wide-ranging audience.

- Be creative, be innovative. We encourage presenters to be innovative in how they structure their own presentation within these guidelines. Inventive presentation styles are particularly desired.

- Avoid PowerPointitis. Multimedia presentation technology will be available for slides, video clips or other imaging but "death by PowerPoint" is discouraged. (As a general rule, no slide should have more than 15 words on it.)

- The time for questions is over. There will be no question and answer time after each presentation. Instead there will be breaks between sessions intended for thinking and discussion with attendees.
- Keep it non-commercial. No sales speeches or plugs for your organization, product or service.

- Practice makes perfect. Please rehearse your presentation before the meeting. If possible ATA would like to receive a video of your presentation in advance so we can provide suggestions.

Here are some "Gold Standard" examples of the range of presentations that might be proposed for the Fall Forum. Don't be intimidated by the level of quality or the specific topic of these examples. They were selected to show possible different formats.

- "Telemedicine via HIE Image Sharing" by Julie Hall-Barrow, EdD (Best Presentation - 2011 ATA Fall Forum)

- "mSinging for Health" by Andrew Tubman, CMT (Most Innovative Presentation - 2011 ATA Fall Forum)

- "The Obesity Crisis" an interview with David Kirchhoff (Interview format with two stage presenters)

- $\quad$ TEDMED Presentation by Walt Mossberg (an outstanding talk but delivered informally)

- " "If Air Travel Worked Like Healthcare" (a very well done and hilarious skit) 
Presenters pay a reduced registration fee of $\$ 100$ for the meeting. ATA does not pay for travel of speakers. We expect to receive many abstract submissions for this event and creativity will be the key determinant in the selection of presentations. ATA will use a panel of telemedicine leaders to evaluate submissions and decide what will be presented. They will be looking for ideas and presenters that are interesting, relevant and thoughtprovoking.

\section{FOR MORE INFORMATION VISIT:}

http://www.americantelemed.org/i4a/pages/index. cfm?pagelD=3965 